Fixed Point Theory, 18(2017), No. 1, 107-126

http://www.math.ubbcluj.ro/ nodeacj/sfptcj.html

\title{
FIXED POINT THEOREMS IN CONES UNDER LOCAL CONDITIONS
}

\author{
ABDELHAMID BENMEZAÏ \\ Faculty of Mathematics, USTHB, Algiers, Algeria \\ E-mail: aehbenmezai@gmail.com
}

\begin{abstract}
We provide in this paper new fixed theorems for operators leaving invariant a cone in a Banach space. The main conditions in these new results are imposed on the behavior of the operator at 0 and $\infty$.
\end{abstract}

Key Words and Phrases: Cones, fixed point index theory, BVPs.

2010 Mathematics Subject Classification: 47H10, 47H11, 34B15.

Acknowledgement. The author would like to thank his laboratory, Fixed Point Theory and Applications, for supporting this work.

\section{REFERENCES}

[1] H. Amann, Fixed points of asymptoticaly linear maps in ordered Banach spaces, J. Functional Anal., 14(1973), 162-171.

[2] N. Benkaci-Ali, A. Benmezai, S. K. Ntouyas, Eigenvalue criteria for existence of positive solutions to singular third-order BVPs via the index-jump property, Commun. Appl. Nonl. Anal., $\mathbf{2 0}(2013)$, no. 2, 55-74.

[3] N. Benkaci-Ali, A. Benmezai, S.K. Ntouyas, Eigenvalue criteria for existence of a positive solution to a singular three point BVP, J. Abstract Diff. Eq. Appl., 2(2012), no. 2, 1-8.

[4] A. Benmezai, Positive solutions for a second order two point boundary value problem, Commun. Appl. Anal., 14(2010), no. 2, 177-190.

[5] A. Benmezai, W. Esserhane, J. Henderson, Existence of positive solutions for singular second order boundary value problems under eigenvalue criteria, Dyn. Contin. Discrete Impuls. Syst. Ser. A Math. Anal., 20(2013), 709-725.

[6] A. Benmezai, John R. Graef, L. Kong, Positive solutions to a two point singular boundary value problem, Diff. Eq. Appl., 3(2011), no. 3, 347-373.

[7] A. Benmezai, J.R. Graef, L. Kong, Positive solutions for the abstract Hammerstein equations and applications, Commun. Math. Anal., 16(2014), no. 1, 47-65.

[8] A. Benmezai, S. Mechrouk, Positive solutions for the nonlinear abstract Hammerstein equation and application to $\phi$-Laplacian BVPs, Nonlinear Diff. Eq. Appl., 20(2013), 489-510.

[9] K. Deimling, Nonlinear Functional Analysis, Springer-Verlag, 1985.

[10] D. Guo, V. Lakshmikantaham, Nonlinear Problems in Abstract Cones, Academic Press, San Diego, 1988.

[11] M.A. Krasnosel'skii, Positive Solutions of Operator Equations, P. Noordhoff, Groningen, 1964.

[12] R.D. Nussbaum, Periodic solutions of some nonlinear integral equations, Proceedings of International Symposium on Dynamical Systems, Gainesville, FL, 1976, Academic Press, New York, $1977,221-249$. 
[13] J.R.L. Webb, Solutions of nonlinear equations in cones and positive linear operators, J. London Math. Soc., 82(2010), no. 2, 420-436.

[14] J.R.L. Webb, A class of positive linear operators and applications to nonlinear boundary value problems, Topol. Meth. Nonlinear Anal., 39(2012), 221-242.

[15] E. Zeidler, Nonlinear Functional Analysis and Its Applications, Vol. I, Fixed Point Theorems, Springer-Verlag, New-York 1986.

Received: June 24, 2014; Accepted: April 30, 2015. 